\title{
CD200: a putative therapeutic target in cancer
}

\author{
Moreaux Jérôme ${ }^{\star \ddagger}$, Veyrune Jean Luc, Reme Thierry ${ }^{\star \ddagger}$, De Vos John ${ }^{\star \ddagger}$, Klein \\ Bernard $^{\star \dagger \ddagger}$
}

${ }^{*} \mathrm{CHU}$ Montpellier, Institute of Research in Biotherapy, Montpellier, FRANCE;

‡ INSERM, U847, Montpellier, F-34197 France;

† Université MONTPELLIER1, UFR Médecine, Montpellier, France;

Corresponding author: Bernard KLEIN

Institut de Recherches en Biothérapie

CHU Montpellier, Hopital St Eloi

Av Augustin Fliche

34285 MONTPELLIER Cedex 5

FRANCE

Phone: +33467330190

Fax: + 33467337905

e-mail: klein@montp.inserm.fr

This work was supported by grants from the Ligue Nationale Contre Le Cancer (équipe labellisée), Paris, France (http://www.ligue-cancer.net) and by INCA (Paris, France).

Abstract word count: 146 words

Text character count: 3119 words 


\section{Abstract}

CD200 was recently described as a new prognosis factor in multiple myeloma and acute myeloid leukemia. CD200 is a membrane glycoprotein that imparts an immunoregulatory signal through CD200R, leading to the suppression of T-cellmediated immune responses. We investigated the expression of CD200 in cancer using publicly available gene expression data. CD200 gene expression in normal or malignant human tissues or cell lines was obtained from the Oncomine Cancer Microarray database, Amazonia database and the ITTACA database. We found significant overexpression of CD200 in renal carcinoma, head and neck carcinoma, testicular cancer, malignant mesothelioma, colon carcinoma, MGUS/smoldering myeloma, and in chronic lymphocytic leukemia compared to their normal cells or their tissue counterparts. Moreover, we show that CD200 expression is associated with tumor progression in various cancers. Taken together, these data suggest that CD200 is a potential therapeutic target and prognostic factor for a large array of malignancies. 


\section{Introduction}

Tumor cells may escape from immune control by producing immunosuppressive molecules, lacking $T$ cell costimulatory molecules or downregulating the presentation of tumor peptides through HLA complexes. Two recent studies have shown that the CD200 gene is overexpressed in malignant plasma cells and in acute myeloid leukemia cells in association with bad prognoses [1].

CD200 is type 1a transmembrane protein, related to the B7 family of costimulatory receptors, with two extracellular domains, a single transmembrane region, and a cytoplasmic tail with no known signaling motif. CD200 is expressed by thymocytes, activated T cells, B cells, dendritic cells, endothelial cells and neurons [2]. The expression of the receptor for CD200 (CD200R1) is restricted to monocyte/macrophage lineage and certain populations of $T$ cells [3]. Three other genes, closely related to CD200R1 and termed CD200R2-4, have been identified, but the function of the encoded proteins, in particular their ability to bind CD200, is not known [4]. Interaction of CD200 with its receptor imparts an immunosuppressive signal leading to inhibition of macrophages [5;6], induction of regulatory $T$ cells [7], switching of cytokine profiles from Th1 to Th2 [8] and inhibition of tumor-specific T cell immunity. In a murine model [9], an increase in CD200 expression in both hepatic and splenic dendritic cells (DCs) results in increased survival of renal allografts following portal vein immunization with alloantigen. This tolerigenic effect was reversed by a monoclonal antibody to CD200 [10]. CD200-deficient mice have a compromised capacity to down-regulate the activation of antigen presenting cells. This results in chronic central nervous system inflammation, which causes an exaggerated inflammatory response to trauma and an increased susceptibility to develop both experimental autoimmune encephalitis and collagen-induced arthritis 
[5]. More recently, Gorczynski et al. demonstrated that anti-CD200R (2-4) monoclonal antibodies (MoAb) promote the development of DCs and have the capacity to induce regulatory $\mathrm{T}$ cells (Treg) and directly augment the production of Treg in the thymus [7]. CD200 is also involved in the immunosuppression in B cell neoplasias. B-cell chronic lymphocytic leukemia cells express CD200, which leads to the inhibition of the Th1 response in mixed lymphocyte reactions [11]. More recently, Kretz-Rommel et al. demonstrated that CD200 expression in Burkitt's lymphoma cell lines prevents the rejection of tumor cells by human PBMC in a NOD/SCID hu-mouse model [12].

These data demonstrate that CD200 is a potent immunosuppressor in autoimmune, transplantation and tumor settings. Therefore, we looked for CD200 expression in various cancers compared to their normal tissue or cell counterparts and in association with staging.

\section{Materials and methods}

\section{Databases}

CD200 gene expression in normal or malignant human tissues or cell lines was obtained from the Oncomine Cancer Microarray database (http://www.oncomine.org) [13], Amazonia database (http://amazonia.montp.inserm.fr/) [14] and the ITTACA database (Integrated Tumor Transcriptome Array and Clinical data Analysis) developed by the Institute Curie Bioinformatics group and the Institute Curie, CNRS UMR144 [15] (http://bioinfo-out.curie.fr/ittaca/). Only gene expression data obtained from a single study using the same methodology were compared. All data were log transformed, median centred per array, and the standard deviation was normalized to one per array [16]. 


\section{Statistical analysis}

Statistical comparisons were done with Mann-Whitney or Student t-tests.

\section{Results and Discussion}

CD200 expression was analyzed in normal tissues using Affymetrix published data from Su et al [17]. The majority of tissues were negative for CD200 expression. CD200 was expressed at low levels by CD34 hematopoietic progenitors, tonsil, DC, cardiac myocytes, lymph node, peripheral B cells and the uterus. The brain and placenta were highly positive for CD200 expression (Supplementary figure S1). We also investigated the expression of CD200 in normal tissues using non Affymetrix published data from Shyamsundar et al [18]. CD200 is highly expressed in brain as observed previously but also in the fallopian tube and thyroid. Bladder, lymph node, thymus, tonsil, uterus and ovary were also positive for CD200 expression (Supplementary figure S1).

We investigated the expression of CD200 in cancer using publicly available gene expression data. CD200 expression by microarray analysis was already validated in MM and in acute myeloid leukemia by real time RT-PCR and flow cytometry, and the data sets were highly correlative $[1 ; 19]$. We found significant overexpression of CD200 in renal carcinomas compared to normal kidneys [20]; $P=1.9 \mathrm{E}-6)$, in head and neck carcinomas compared to normal oral mucosa [21]; $P=1.8 \mathrm{E}-7$ ), in testicular cancer compared to normal testes [22]; $P=4 \mathrm{E}-12$ and [23] $P=1.9 E-5$ ), in malignant mesothelioma compared to normal pleura [24]; $P=.002$ ), in colon carcinoma compared to normal colonic epithelia [25] ; $\mathrm{P}=0.02)$ and in smoldering myeloma compared to normal plasma cells $[26] ; P=1.8 \mathrm{E}-4)$ confirming our recent study [19] (Figure 1). We found significant overexpression of CD200 in chronic 
lymphocytic leukemia compared to normal B cells [27] ; $P=4.8 \mathrm{E}-17$ ) (Figure 1). In contrast, the expression of CD200 in Burkitt lymphoma, diffuse large B cell lymphoma and follicular lymphoma was not different from that in normal B cells.

Recently, Tonks A et al.[1] and our group [19] demonstrated that CD200 expression is associated with a poor prognosis in $\mathrm{AML}$ and $\mathrm{MM}$ respectively. We searched to identify if CD200 expression could be associated with tumor progression in other cancers (Figure 2). Indeed, we found that CD200 is significantly overexpressed in invasive bladder carcinoma compared to superficial bladder carcinoma in two independent studies $(P=9.1 \mathrm{E}-6$ and $P=0.001)$ [28; 29]. $C D 200$ was also overexpressed in patients presenting advanced lung cancer stages (stages II, III and IV) compared to stage I [30]. Chronic myelogenous leukemia is grouped into several phases: the chronic phase, the accelerated phase and the blast crisis phase consistent with the progression of the disease. CD200 appears to be significantly overexpressed in CML cells in the accelerated phase compared to the chronic phase $(P=0.03)$ and in blast crisis compared to the accelerated phase $(P=0.04)$ and chronic phase $(P=3.5 \mathrm{E}-7)$ [31]. In $\mathrm{CML}, C D 200$ expression is upregulated during disease progression. In breast cancer, CD200 is overexpressed in patients presenting metastases at 5 years compared to patients without metastases $(P=$ 0.009) [32] and in relapsing patients compared to patients without progression $(P=$ 0.004) [33]. Metastatic melanoma showed and overexpression of CD200 compared to primary melanomas and normal melanocytes $(P=0.01)$ [34]. Prostate cancer progression was also characterized by an enhanced expression of $C D 200(P=0.01)$ [35].

The analysis reported here demonstrates that $C D 200$ mRNA is overexpressed in at least 8 cancers compared to their normal counterparts, and within a given tumor 
category, is associated with a bad prognosis. A recent study reported the coexpression of CD200 with cancer stem cell markers found on prostate, breast, brain and colon cancers [36]. Given the immunosuppressive role of CD200, overexpression of CD200 in cancer tissues may facilitate an escape from the immune response and provide a mechanism whereby cancer stem cells are able to avoid detection by the immune system and remain as residual disease. As indicated above, antibodies to CD200 can abrogate its immunosuppressive effect, and in particular, restore tumor immune control in murine models. Thus, the targeting of CD200 may be promising in a large number of cancers. CD200 emerges as a candidate target in a very wide panel of malignancies. 


\section{References}

[1] A. Tonks, R. Hills, P. White, B. Rosie, K.I. Mills, A.K. Burnett, and R.L. Darley, CD200 as a prognostic factor in acute myeloid leukaemia. Leukemia 21 (2007) 566-8.

[2] A.N. Barclay, G.J. Wright, G. Brooke, and M.H. Brown, CD200 and membrane protein interactions in the control of myeloid cells. Trends Immunol 23 (2002) 285-90.

[3] G.J. Wright, H. Cherwinski, M. Foster-Cuevas, G. Brooke, M.J. Puklavec, M. Bigler, Y. Song, M. Jenmalm, D. Gorman, T. McClanahan, M.R. Liu, M.H. Brown, J.D. Sedgwick, J.H. Phillips, and A.N. Barclay, Characterization of the CD200 receptor family in mice and humans and their interactions with CD200. J Immunol 171 (2003) 3034-46.

[4] R.M. Gorczynski, CD200 and its receptors as targets for immunoregulation. Curr Opin Investig Drugs 6 (2005) 483-8.

[5] R.M. Hoek, S.R. Ruuls, C.A. Murphy, G.J. Wright, R. Goddard, S.M. Zurawski, B. Blom, M.E. Homola, W.J. Streit, M.H. Brown, A.N. Barclay, and J.D. Sedgwick, Downregulation of the macrophage lineage through interaction with OX2 (CD200). Science 290 (2000) 1768-71.

[6] M.C. Jenmalm, H. Cherwinski, E.P. Bowman, J.H. Phillips, and J.D. Sedgwick, Regulation of myeloid cell function through the CD200 receptor. J Immunol 176 (2006) 191-9.

[7] R.M. Gorczynski, L. Lee, and I. Boudakov, Augmented Induction of CD4+CD25+ Treg using monoclonal antibodies to CD200R. Transplantation 79 (2005) 1180-3.

[8] L. Gorczynski, Z. Chen, J. Hu, Y. Kai, J. Lei, V. Ramakrishna, and R.M. Gorczynski, Evidence that an OX-2-positive cell can inhibit the stimulation of type 1 cytokine production by bone marrow-derived B7-1 (and B7-2)-positive dendritic cells. J Immunol 162 (1999) 774-81.

[9] R.M. Gorczynski, Z. Chen, X.M. Fu, and H. Zeng, Increased expression of the novel molecule OX-2 is involved in prolongation of murine renal allograft survival. Transplantation 65 (1998) 1106-14.

[10] R.M. Gorczynski, Z. Cohen, X.M. Fu, and J. Lei, Anti-rat OX-2 blocks increased small intestinal transplant survival after portal vein immunization. Transplant Proc 31 (1999) 577-8.

[11] J.R. McWhirter, A. Kretz-Rommel, A. Saven, T. Maruyama, K.N. Potter, C.I. Mockridge, E.P. Ravey, F. Qin, and K.S. Bowdish, Antibodies selected from combinatorial libraries block a tumor antigen that plays a key role in immunomodulation. Proc Natl Acad Sci U S A 103 (2006) 1041-6.

[12] A. Kretz-Rommel, F. Qin, N. Dakappagari, E.P. Ravey, J. McWhirter, D. Oltean, S. Frederickson, T. Maruyama, M.A. Wild, M.J. Nolan, D. Wu, J. Springhorn, and K.S. Bowdish, CD200 Expression on Tumor Cells Suppresses Antitumor Immunity: New Approaches to Cancer Immunotherapy. J Immunol 178 (2007) 5595-605.

[13] D.R. Rhodes, J. Yu, K. Shanker, N. Deshpande, R. Varambally, D. Ghosh, T. Barrette, A. Pandey, and A.M. Chinnaiyan, Large-scale meta-analysis of cancer microarray data identifies common transcriptional profiles of neoplastic transformation and progression. Proc Natl Acad Sci U S A 101 (2004) 9309-14.

[14] S. Assou, T. Lecarrour, S. Tondeur, S. Strom, A. Gabelle, S. Marty, L. Nadal, V. Pantesco, T. Reme, J.P. Hugnot, S. Gasca, O. Hovatta, S. Hamamah, B. Klein, and J. De Vos, A meta-analysis of human embryonic stem cells transcriptome integrated into a web-based expression atlas. Stem Cells (2007). 
[15] A. Elfilali, S. Lair, C. Verbeke, P. La Rosa, F. Radvanyi, and E. Barillot, ITTACA: a new database for integrated tumor transcriptome array and clinical data analysis. Nucleic Acids Res 34 (2006) D613-6.

[16] D.R. Rhodes, J. Yu, K. Shanker, N. Deshpande, R. Varambally, D. Ghosh, T. Barrette, A. Pandey, and A.M. Chinnaiyan, ONCOMINE: a cancer microarray database and integrated data-mining platform. Neoplasia 6 (2004) 1-6.

[17] A.I. Su, T. Wiltshire, S. Batalov, H. Lapp, K.A. Ching, D. Block, J. Zhang, R. Soden, M. Hayakawa, G. Kreiman, M.P. Cooke, J.R. Walker, and J.B. Hogenesch, A gene atlas of the mouse and human protein-encoding transcriptomes. Proc Natl Acad Sci U S A 101 (2004) 6062-7.

[18] R. Shyamsundar, Y.H. Kim, J.P. Higgins, K. Montgomery, M. Jorden, A. Sethuraman, M. van de Rijn, D. Botstein, P.O. Brown, and J.R. Pollack, A DNA microarray survey of gene expression in normal human tissues. Genome Biol 6 (2005) R22.

[19] J. Moreaux, D. Hose, T. Reme, E. Jourdan, M. Hundemer, E. Legouffe, P. Moine, P. Bourin, M. Moos, J. Corre, T. Mohler, J. De Vos, J.F. Rossi, H. Goldschmidt, and B. Klein, CD200 is a new prognostic factor in multiple myeloma. Blood 108 (2006) 4194-7.

[20] M.E. Lenburg, L.S. Liou, N.P. Gerry, G.M. Frampton, H.T. Cohen, and M.F. Christman, Previously unidentified changes in renal cell carcinoma gene expression identified by parametric analysis of microarray data. BMC Cancer 3 (2003) 31.

[21] M.A. Ginos, G.P. Page, B.S. Michalowicz, K.J. Patel, S.E. Volker, S.E. Pambuccian, F.G. Ondrey, G.L. Adams, and P.M. Gaffney, Identification of a gene expression signature associated with recurrent disease in squamous cell carcinoma of the head and neck. Cancer Res 64 (2004) 55-63.

[22] J.E. Korkola, J. Houldsworth, R.S. Chadalavada, A.B. Olshen, D. Dobrzynski, V.E. Reuter, G.J. Bosl, and R.S. Chaganti, Down-regulation of stem cell genes, including those in a $200-\mathrm{kb}$ gene cluster at $12 \mathrm{p} 13.31$, is associated with in vivo differentiation of human male germ cell tumors. Cancer Res 66 (2006) 820-7.

[23] R.I. Skotheim, G.E. Lind, O. Monni, J.M. Nesland, V.M. Abeler, S.D. Fossa, N. Duale, G. Brunborg, O. Kallioniemi, P.W. Andrews, and R.A. Lothe, Differentiation of human embryonal carcinomas in vitro and in vivo reveals expression profiles relevant to normal development. Cancer Res 65 (2005) 5588-98.

[24] G.J. Gordon, G.N. Rockwell, R.V. Jensen, J.G. Rheinwald, J.N. Glickman, J.P. Aronson, B.J. Pottorf, M.D. Nitz, W.G. Richards, D.J. Sugarbaker, and R. Bueno, Identification of novel candidate oncogenes and tumor suppressors in malignant pleural mesothelioma using large-scale transcriptional profiling. Am J Pathol 166 (2005) 1827-40.

[25] T.T. Zou, F.M. Selaru, Y. Xu, V. Shustova, J. Yin, Y. Mori, D. Shibata, F. Sato, S. Wang, A. Olaru, E. Deacu, T.C. Liu, J.M. Abraham, and S.J. Meltzer, Application of cDNA microarrays to generate a molecular taxonomy capable of distinguishing between colon cancer and normal colon. Oncogene 21 (2002) 4855-62.

[26] F. Zhan, B. Barlogie, V. Arzoumanian, Y. Huang, D.R. Williams, K. Hollmig, M. Pineda-Roman, G. Tricot, F. van Rhee, M. Zangari, M. Dhodapkar, and J.D. Shaughnessy, Jr., Gene-expression signature of benign monoclonal gammopathy evident in multiple myeloma is linked to good prognosis. Blood 109 (2007) 1692-700.

[27] U. Klein, Y. Tu, G.A. Stolovitzky, M. Mattioli, G. Cattoretti, H. Husson, A. Freedman, G. Inghirami, L. Cro, L. Baldini, A. Neri, A. Califano, and R. Dalla-Favera, Gene expression profiling of $\mathrm{B}$ cell chronic lymphocytic leukemia reveals a homogeneous phenotype related to memory B cells. J Exp Med 194 (2001) 1625-38. 
[28] O. Modlich, H.B. Prisack, G. Pitschke, U. Ramp, R. Ackermann, H. Bojar, T.A. Vogeli, and M.O. Grimm, Identifying superficial, muscle-invasive, and metastasizing transitional cell carcinoma of the bladder: use of cDNA array analysis of gene expression profiles. Clin Cancer Res 10 (2004) 3410-21.

[29] M. Sanchez-Carbayo, N.D. Socci, J. Lozano, F. Saint, and C. Cordon-Cardo, Defining molecular profiles of poor outcome in patients with invasive bladder cancer using oligonucleotide microarrays. J Clin Oncol 24 (2006) 778-89.

[30] A. Bhattacharjee, W.G. Richards, J. Staunton, C. Li, S. Monti, P. Vasa, C. Ladd, J. Beheshti, R. Bueno, M. Gillette, M. Loda, G. Weber, E.J. Mark, E.S. Lander, W. Wong, B.E. Johnson, T.R. Golub, D.J. Sugarbaker, and M. Meyerson, Classification of human lung carcinomas by mRNA expression profiling reveals distinct adenocarcinoma subclasses. Proc Natl Acad Sci U S A 98 (2001) 13790-5.

[31] J.P. Radich, H. Dai, M. Mao, V. Oehler, J. Schelter, B. Druker, C. Sawyers, N. Shah, W. Stock, C.L. Willman, S. Friend, and P.S. Linsley, Gene expression changes associated with progression and response in chronic myeloid leukemia. Proc Natl Acad Sci U S A 103 (2006) 2794-9.

[32] Y. Wang, J.G. Klijn, Y. Zhang, A.M. Sieuwerts, M.P. Look, F. Yang, D. Talantov, M. Timmermans, M.E. Meijer-van Gelder, J. Yu, T. Jatkoe, E.M. Berns, D. Atkins, and J.A. Foekens, Gene-expression profiles to predict distant metastasis of lymph-nodenegative primary breast cancer. Lancet 365 (2005) 671-9.

[33] L.J. van 't Veer, H. Dai, M.J. van de Vijver, Y.D. He, A.A. Hart, M. Mao, H.L. Peterse, K. van der Kooy, M.J. Marton, A.T. Witteveen, G.J. Schreiber, R.M. Kerkhoven, C. Roberts, P.S. Linsley, R. Bernards, and S.H. Friend, Gene expression profiling predicts clinical outcome of breast cancer. Nature 415 (2002) 530-6.

[34] C. Haqq, M. Nosrati, D. Sudilovsky, J. Crothers, D. Khodabakhsh, B.L. Pulliam, S. Federman, J.R. Miller, 3rd, R.E. Allen, M.I. Singer, S.P. Leong, B.M. Ljung, R.W. Sagebiel, and M. Kashani-Sabet, The gene expression signatures of melanoma progression. Proc Natl Acad Sci U S A 102 (2005) 6092-7.

[35] S.A. Tomlins, R. Mehra, D.R. Rhodes, X. Cao, L. Wang, S.M. Dhanasekaran, S. Kalyana-Sundaram, J.T. Wei, M.A. Rubin, K.J. Pienta, R.B. Shah, and A.M. Chinnaiyan, Integrative molecular concept modeling of prostate cancer progression. Nat Genet 39 (2007) 41-51.

[36] B.T. Kawasaki, T. Mistree, E.M. Hurt, M. Kalathur, and W.L. Farrar, Co-expression of the toleragenic glycoprotein, CD200, with markers for cancer stem cells. Biochem Biophys Res Commun (2007). 
Figure legends

Figure 1: CD200 expression in various cancers.

CD200 gene expression in normal kidney, renal carcinoma [20], normal oral mucosa, head and neck carcinoma [21], normal plasma cells, smoldering myeloma [26], normal testis, testicular cancer [22; 23], normal pleura, malignant mesothelioma [24], normal colonic epithelium, colon carcinoma [25], cordblood B cells, IgD naïve B cells, centroblastic B cells, centrocytic B cells, memory B cells, Burkitt lymphoma, diffuse large B cell lymphoma, follicular lymphoma and chronic lymphocytic leukemia [27]. Data sets in a single panel were from the same study. GEP data are log transformed and normalized as previously described [16].

Figure 2: Association between CD200 expression and progression in various cancers.

CD200 gene expression in superficial bladder carcinoma, invasive bladder carcinoma [29], lung cancer [30], chronic myelogenous leukemia [31], breast cancer [32; 33], primary melanoma, metastatic melanoma [34], prostatic intraepithelial neoplasia and prostate carcinoma [35]. Data sets in a single panel were from the same study. GEP data are log transformed and normalized as previously described [16]. 
Figure 1
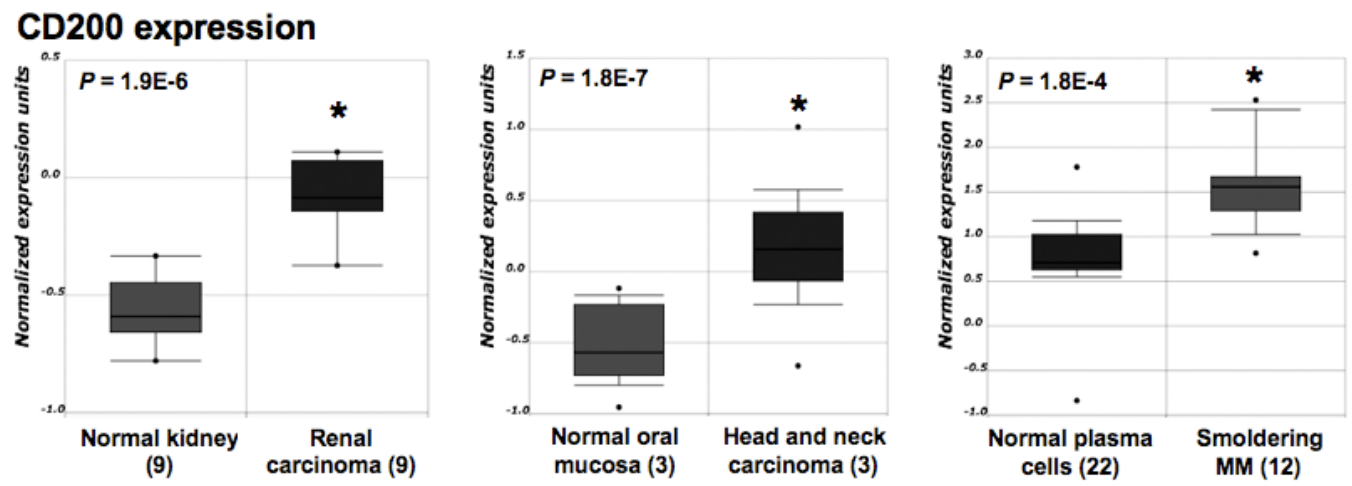

Lenburg et al.BMC Cancer 2003

Ginos et al. Cancer Res 2004

Zhan et al. Blood 2007
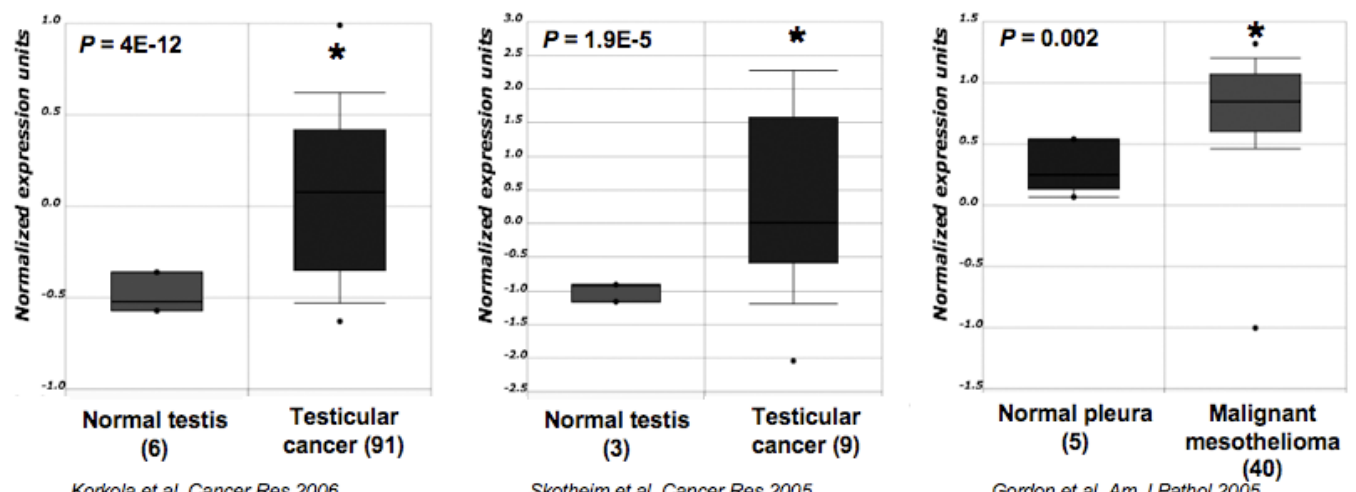

Korkola et al. Cancer Res 2006

Skotheim et al. Cancer Res 2005

\section{CD200 expression}
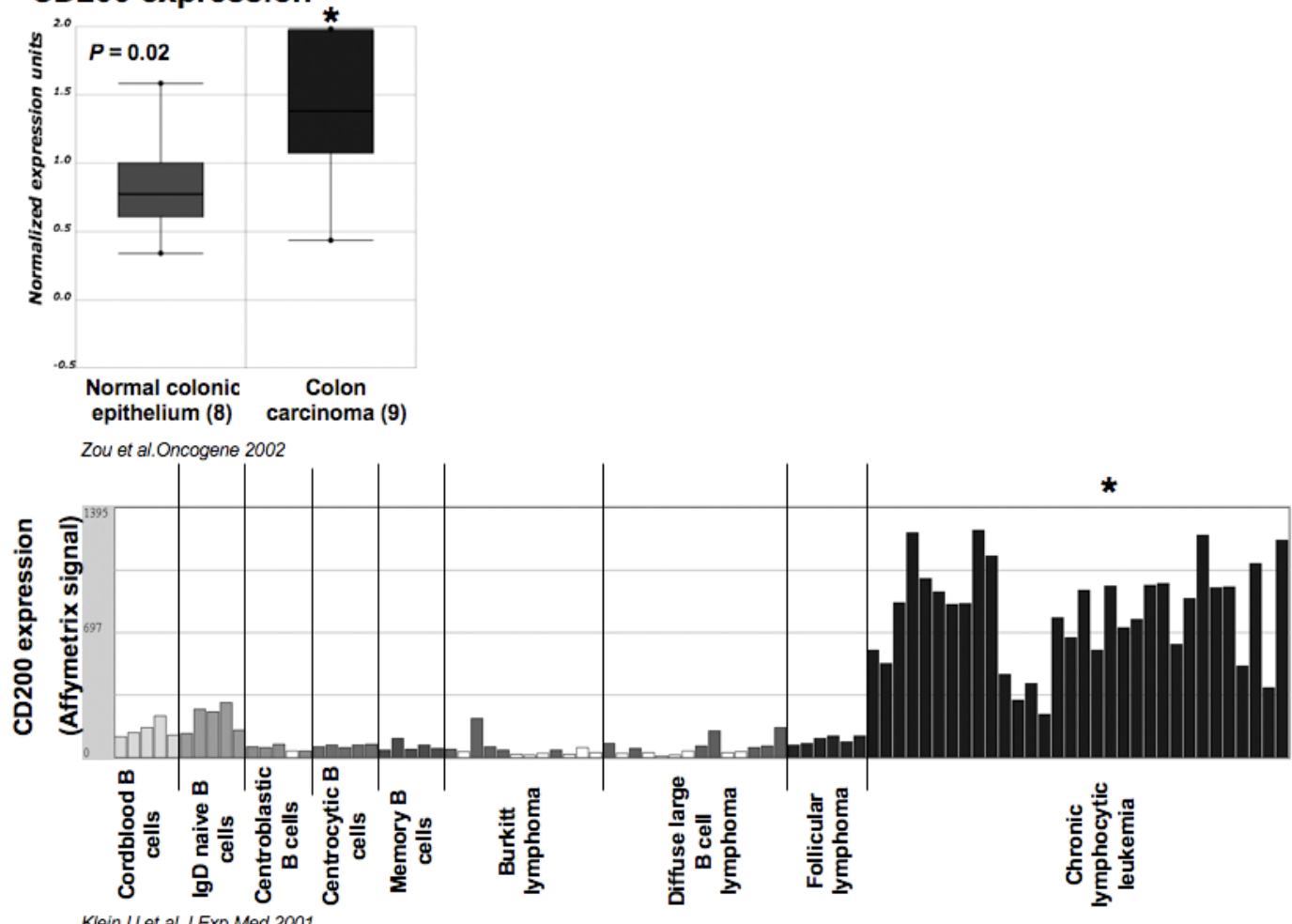
Figure 2

\section{CD200 expression}

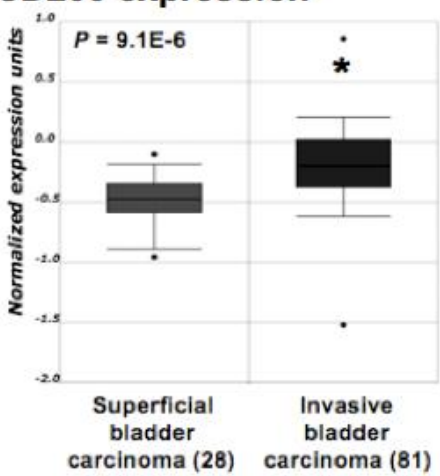

Sanchez-Carbayo et al. J clin Oncol 2006

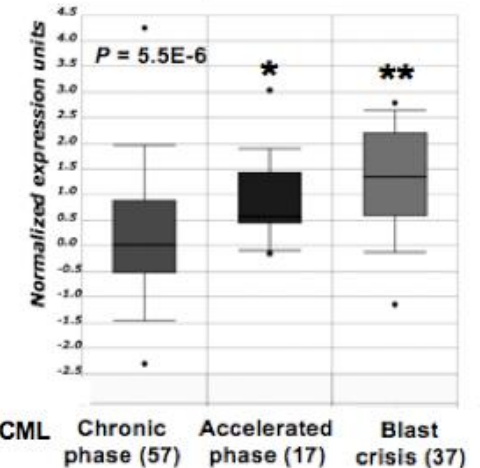

phase (57) phase (17) crisis (37)

Radich JP et al. Proc Natl Acad Scl 2006

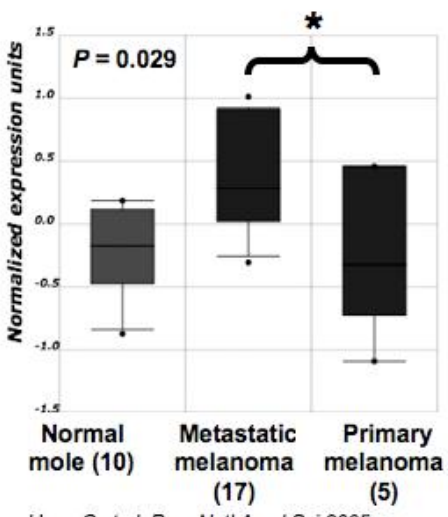

Hagq Cet al. Proc Natl Acad Sci 2005

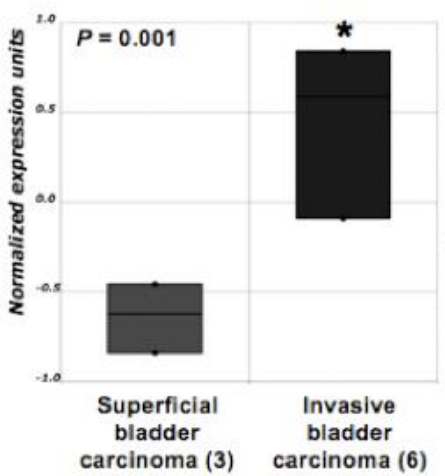

Modlich O et al. Clin Cancer Res 2004

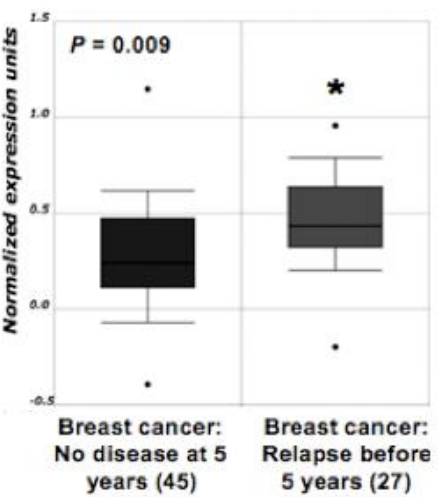

Wang $Y$ et al. Lancet 2005

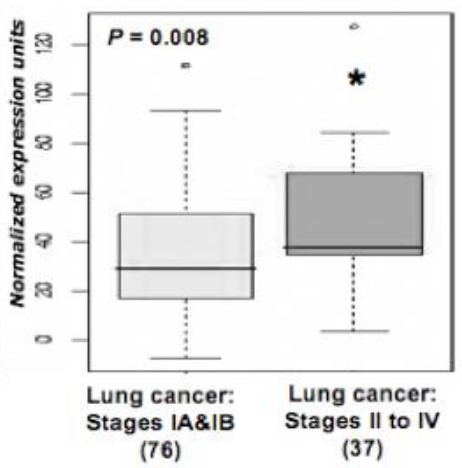

Bhattacharjee A et al. Proc Natl Acad Sci 2001

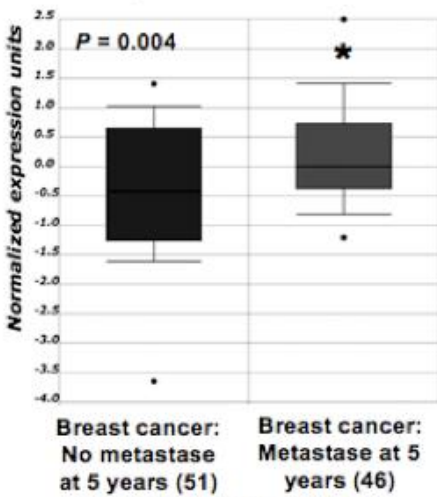

years (46)

Van ' $t$ Veer $L j$ et al. Nature 2002

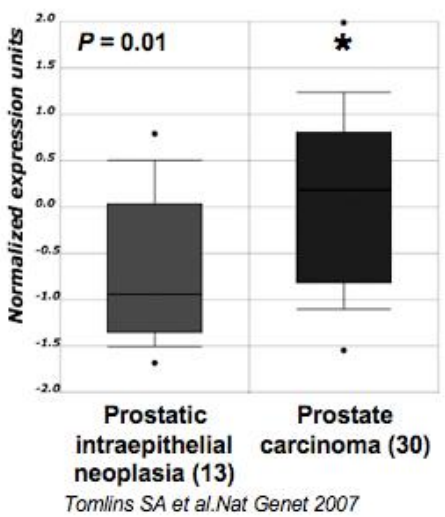

